\title{
Trends in Wind-Power Desalination for Water Supply
}

\author{
Fabrícia de S. Moreira ${ }^{1 *}$, Adelaide Maria de S. Antunes ${ }^{1,2}$, Marcos Aurélio V. de Freitas ${ }^{3}$ \\ ${ }^{1}$ Program of Engineering of Chemical and Biochemical Processes, School of Chemistry, Universidade Federal do Rio de Janeiro, \\ Rio de Janeiro, Brazil \\ ${ }^{2}$ Instituto Nacional de Propriedade Industrial (INPI), Rio de Janeiro, Brazil \\ ${ }^{3}$ Energy Planning Program, COPPE, Universidade Federal do Rio de Janeiro, Rio de Janeiro, Brazil \\ Email: ^^abricia.moreira@ivig.coppe.ufrj.br
}

How to cite this paper: de S. Moreira, F. and de S. Antunes, A.M. and de Freitas, M.A.V. (2019) Trends in Wind-Power Desalination for Water Supply. Journal of Environmental Protection, 10, 807-820. https://doi.org/10.4236/jep.2019.106048

Received: April 23, 2019

Accepted: June 18, 2019

Published: June 21, 2019

Copyright $\odot 2019$ by author(s) and Scientific Research Publishing Inc. This work is licensed under the Creative Commons Attribution International License (CC BY 4.0).

http://creativecommons.org/licenses/by/4.0/

(c) (i) Open Access

\begin{abstract}
Water scarcity is a threat for mankind and its symptoms have been aggravated by several factors such as climate change effects, increase in population and accelerated urbanization. Among the alternatives of water supply, the desalination has become one of the most sustainable solutions to provide freshwater. However, the process of desalination requires high quantities of energy and the use of renewable energy sources can make the technology affordable for regions characterized by freshwater scarcity where the supply from electricity is not accessible. In this context, wind power can be singled out because of the constant innovations and progress of the wind power industry, which grows rapidly worldwide. This study aims to use patent applications for the technological forecasting of wind-powered desalination in order to analyse its innovation potential. China is the leader country in the technological development of this field, accounting for almost $80 \%$ of patent applications in the last 17 years. The patents analysis showed that innovations are being developed to combine the wind power, mainly, with Reverse Osmosis technology. This study also shows the immense potential of integrating of these two technologies as a strategic alternative for remote regions affected by a lack of freshwater and with no electricity access.
\end{abstract}

\section{Keywords}

Water Scarcity, Desalination, Wind Energy, Technological Trends, Patent Applications

\section{Introduction}

Water is available on the surface as well as underneath it, and it is a fundamental 
resource that cannot be replaced because of its many uses, such as drinking, irrigation, domestic purposes, generation of hydroelectricity, and industrial purposes. According to the United States Geological Survey (USGS), nearly $97 \%$ of water is found in the oceans, which are saline in nature, and the remaining $3 \%$ is freshwater [1].

Water scarcity has affected humanity for decades, but over the last years it increased due to climate anomalies, global warming, population growth and pollution from natural sources. The need for freshwater tops the global list of critical problems together with climate change effects. In the developing world, many regions suffer from shortages of freshwater and energy supplies. It is estimated that 3.6 billion people (almost half the world's population) live in areas that have a potential shortage of water for at least one month per year, and this population may increase to between 4.8 billion and 5, 7 billion by 2050 [2]. About one billion people lack access to purified drinking water, and the vast majority of these people live in rural and remote areas of low population density, where it is hard to install traditional clean water solutions. Unfortunately, in addition to being scarce, freshwater resources are also unevenly distributed geographically worldwide [3] [4].

According to the United Nations World Water Development Report released in 2015 , by 2050 , the global water demand is projected to increase by $55 \%$, mainly due to growing demands from manufacturing, thermal electricity generation and domestic use, while the amount of water available will stay the same [2]. In order to add freshwater stocks to those existing presently, the only possible way is to purify the highly saline ocean waters [1]. Desalination is known as one of mankind's earliest forms of water treatment, and it has become one of the most sustainable alternative solutions to provide freshwater. Since water supply risks entering a serious crisis, desalination is already part of the strategic programs of many countries. Some cities obtain their freshwater supply completely from seawater-in spite of the high costs, it is their only alternative. It is well known that $70 \%$ of world's desalination plants are located in the Middle East region. On the global scale, about 18,426 desalination plants now operate in over 150 countries with a total capacity of 86.8 million $\mathrm{m}^{3} / \mathrm{d}$ [5] [6].

Seawater or brackish water can be desalinized and supplied in large quantities for domestic supply and industrial uses. However, these processes originate other issues, mainly the high energy consumption [7]. The process of desalination requires high quantities of energy, supplied mainly from conventional fuels. As a result, it becomes costlier than obtaining surface and ground water through other methods.

Desalination is a process in which saline water is separated into two parts using different forms of energy, one that has a low concentration of dissolved salts (freshwater), and the other which has a much higher concentration of dissolved salts than the original feed water (brine concentrate) [8]. Saline water is classified as either brackish water or seawater depending on the salinity and water source. The desalination can occur in many forms, such as thermal and mem- 
brane processes. Thermal processes are based on the change of the state of water, among which the following methods stand out: Multi-Stage Flash Distillation (MSFD), Multiple Effect Distillation (MED) and Mechanical Vapour Compression (MVC). Membrane processes, in their turn, are based on the membrane's capacity of selectively separating salts from water [9]. In general, it is possible to understand the membrane as a barrier that separates two phases and that restricts the transportation of one or more chemical elements partially or entirely [10]. Among the processes of membrane separation, Electrodialysis (ED) and Reverse Osmosis (RO) can be singled out. Electrodialysis is based on the passage of water through a recipient that contains two poles under the influence of an electrical field, in addition to successive semipermeable membranes. With the electrical field, the positive and negative ions of the dissociated salt molecules migrate to the respective poles and are separated from the water by the action of the membranes. In reverse osmosis, the process is based on adding pressure to the water that will be treated, making it pass through the semipermeable membrane and separating the water from the solute [9].

In thermal and membrane processes, the main obstacle for the dissemination of desalination is their high energy consumption. The desalination of salty water requires significant amounts of electrical or thermal energy, depending on the process [11]. Today most of the energy supply for desalination is produced from fossil fuels that are harmful to the environment as they emit carbon dioxide $\left(\mathrm{CO}_{2}\right)$, and only less than $1 \%$ of the energy supply comes from renewables [12]. According to [11], the use of a renewable energy source can reduce significantly the operation costs of desalination processes, making the technology affordable for regions characterized by freshwater scarcity, mainly where the supply from electricity is not accessible.

In today's carbon-constrained world, with rising awareness of the risks of climate change, clean energy technologies are considered environmentally friendly energy options to sustain socioeconomic development. Additionally, these resources help to assure energy security and to reduce reliance on foreign oil as well as the associated market vulnerabilities [13]. Various non-conventional sources of energy like solar, wind, wave and tidal energy can be used to produce electrical energy for desalination plants driven by electricity. Desalination using biomass and geothermal energies is still being developed, but there are many possible combinations of other renewable energy sources with desalination technologies to produce freshwater [14]. Renewable energy provides energy security without damaging the environment, while the reduction of fossil fuel reserves puts at risk the long-term sustainability of the global economy. As a result, the use of renewable resources for desalination becomes increasingly appealing, particularly in isolated and dries districts where the use of conventional energy is expensive or unrealistic.

Among the renewable energies, solar and wind energy occupy the higher fraction of the renewable energy utilization in the desalination field [15]. In this sense, the wind energy can be singled out because of the constant innovations 
and development of the wind power industry, which has grown rapidly and consistently worldwide, contributing to the development of new market sectors and job creation. The average growth of the wind generated power capacity worldwide between 2005 and 2014 was 23\% per year, reaching a global capacity of $369.6 \mathrm{GW}$ by the end of 2014 [16]. According to the report Renewable Energy Policy Network for the $21^{\text {st }}$ century (REN21), by the end of 2014, wind power represented $3 \%$ of the world's production of electricity [17]. The International Energy Agency predicts that this capacity will reach $18 \%$ by 2050 [18].

Areas with a high wind energy potential like islands and high-altitude zones can be used to produce wind energy to provide freshwater using desalination processes. The electrical or mechanical energy generated by a wind turbine can be used to operate desalination plants, especially in coastal areas with a high wind power potential [19]. Moreover, according to some authors, among the many renewable energy resources, the integration of desalination with wind power has the smallest impact on the environment, representing a $75 \%$ decrease from other energy sources [20]. As a result, in areas with a high wind power potential and that need desalination, wind power is the most appealing energy source.

Wind power generation and desalination are different technologies that can be combined in many ways. The interface between the wind power system and the desalination unit occurs where the energy generated by the wind is transferred to the desalination plant. Since the energy required by desalination significantly affects operational costs, the integration of renewable energy systems with desalination seems to be a strategic option that would enable the use of the technology in many regions. Wind energy can power desalination plants directly or indirectly through four types of energy: electricity, thermal energy, potential gravitational energy and kinematic energy [21].

Electricity is the most commonly used interface between wind power and desalination. After the electricity is converted, the energy of the wind plant can be used in desalination processes such as Reverse Osmosis, Electrodialysis and Vapour Compression [21]. The prototypes of wind-powered desalination systems have been reported in some regions of the world and a range of experiments has been conducted. For example, the city of Perth started the push for wind-powered desalination in Australia. The first plant was put into operation in 2006, and it is located in Kwinana, $40 \mathrm{~km}$ to the south of Perth. The desalination plant produces $150,000 \mathrm{~m}^{3} / \mathrm{d}$, which corresponds to approximately $20 \%$ of the city's water supply. An associated wind farm of $82 \mathrm{MW}$ capacity provides the energy and also produces surplus energy into the grid [22]. A desalination plant in Sydney requires $46 \mathrm{MW}$ at full capacity and is powered by 67 wind turbines having a full capacity of $140 \mathrm{MW}$. It can supply close to $250,000 \mathrm{~m}^{3} / \mathrm{d}$ which is around $15 \%$ of all the water needs for the city [23].

In view of the great potential of the use wind power in desalination units in coastal regions and islands, finding out more about which the main barriers to development of this technology and the trends for the future is clearly worth- 
while.

Technology foresight is one of the most widely used methods for investigating the future use of given technologies, mapping out and giving an overview of a process or production chain [24]. In this research, a foresight study of wind-powered desalination was conducted by investigating patenting activity on the subject. With technological trends and the collection of data from patents, this study aims to identify the main applicant countries, the evolution of the number of applications over time, the international classification of the technological content of the innovations related to desalination driven by wind energy, and the main applicants in this technological field. The research and development trends of wind-powered desalination can represent strategic alternatives to solve water scarcity worldwide in the future.

Patents are excellent indicators of innovation since they can be used to measure results of Research and Development (R \& D), productivity, structure and the development of a specific technology/industry. Since R \& D activities and the number of patent requests are related, it is possible to compare, monitor and analyse the development activities in a specific area or new sector. Statistics on patents have been used to evaluate the results of activities related to innovation. The number of patents granted to a certain company or a certain country reflects its technological progress. Moreover, an analysis of patented technologies can show in which direction technology is changing [25]. The World Intellectual Property Organization (WIPO), governments and scholars in general see the patent applications of a country as an indicator of its technological advances [26].

\section{Methodology}

This study is a technological analysis involving the empirical study of patents applications. In this article, three main steps were carried out. First contact with the theme through a bibliographical review. Reference literature was used to give a picture of the state of the art about the desalination in terms of technologies, installations and challenges of the sector.

The second step is the search of patent applications on the selected database using keywords and International Patent Classification (IPC). The IPC is the international classification system created by the Strasbourg Agreement (1971) which divides technological areas in classes from A to $\mathrm{H}$. Within each class, there are subclasses, main groups and groups in a hierarchical system, with classification for the technological contents of the patents.

Next, an analysis of the retrieved patents applications was performed through of documents reading. Variables as country of origin, year of publication, applicants and main claims were extracted from patent documents. The analysis of the data allowed the identification of the main technological trends of the wind-powered desalination industry.

We retrieved patents applications using the Derwent Innovations Index database, for patents filed between 2000 to October 2017. The Derwent Innovations 
Index (DII) is a commercial database that combines the resources of the Derwent World Patents Index and the Patents Citation Index. It enables the patent and citation searches of inventions in chemical, electrical, electronic, and mechanical engineering. This basis covers over 14.3 million basic inventions from 40 worldwide patent-issuing authorities from 1963 until today.

The search in the database was made using as strategy the following keywords in the title/abstract: (wind) AND (desalting OR desalination), that can be replaced by the radical $\left(\right.$ desal $\left.^{\star}\right)$; and the International Patent Classification (IPC) subgroup C02F-103/08 (seawater for desalination). The objective of this search strategy was to restrict the research only to documents that involved the desalination driven by the wind power.

The patents applications recovered by the search were imported into the software Excel to organize the information in a table and sort them out by selected variable.

\section{Results and Discussion}

The results from the search are presented in graphics and analysed. The search strategy described in the methodology led to 133 patent applications, being that of this total, 38 patent applications are of the utility model ${ }^{1}$ type.

Figure 1 shows how the patenting of technology for this area has developed over the period analysed (2000-2017), considering the priority date, which in general corresponds to the filing date of the first application in the country of origin.

Although the period of analysis lasts from 2000 and 2017, the results of the database show the number of applications started to grow in 2003, and continues to remain high. The number of applications in 2017 is incomplete because the international patent system can only publish the filed patent document after 18 months of the priority date (or up to 30 months if the document is filed through a Patent Cooperation Treaty- $\mathrm{PCT}^{2}$ ). In addition, indexing the application in the search base may take some time and it varies from one base to another.

New applications have been made consistently throughout the period under study, confirming that wind-powered desalination is a technology in advancement. This integration between wind power and desalination is gaining more highlight because of recent environmental concerns. Indeed, the rise in the ${ }^{1}$ In some countries, a utility model system provides protection of so-called "minor inventions" through a system similar to the patent system. Recognizing that minor improvements of existing products, which does not fulfill the patentability requirements, may have an important role in a local innovation system, utility models protect such inventions through granting an exclusive right, which allows the right holder to prevent others from commercially using the protected invention, without his authorization, for a limited period of time. In general, compared with patents, utility model systems require compliance with less stringent requirements (for example, lower level of inventive step), have simpler procedures and offer shorter term of protection [27].

${ }^{2}$ The Patent Cooperation Treaty (PCT) is an international treaty that makes it possible to seek patent protection for an invention simultaneously in each of a large number of countries by filing one "international" patent application and then commencing the national procedure in the countries where protection is sought. 


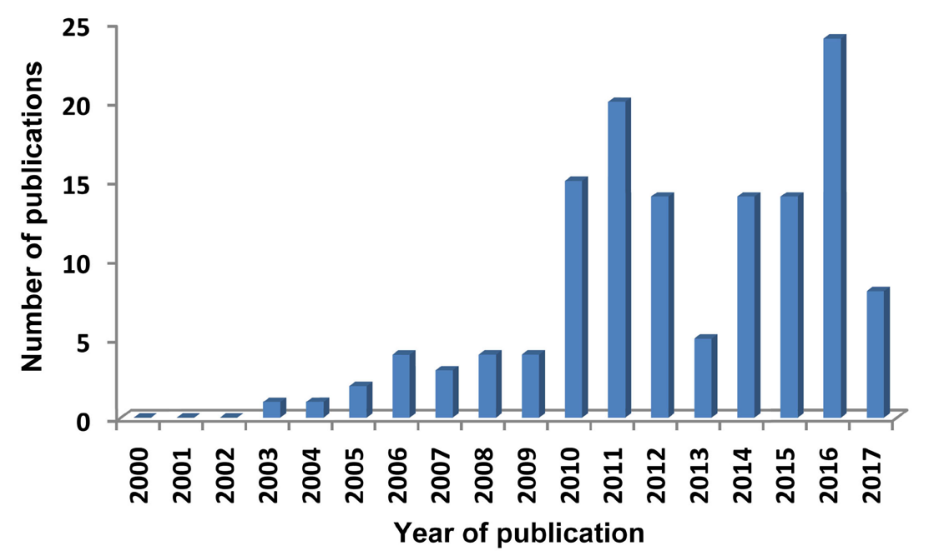

Figure 1. Evolution over time of patent applications of wind-powered desalination of seawater retrieved from the Derwent Innovations Index database, indexed between 2000 and 2017 (own research).

number of patent applications in the last 15 years should be due to the growing need to comply with increasingly stringent legislation in the use the clean energy sources, besides of the intensification of climate change effects that are changing the water availability in the world. The alternative of integration between these two technologies represents one strategic solution to solve the problem of the water scarcity in many regions.

\subsection{Number of Applications per Country of Origin}

Figure 2 shows the number of patent applications on the subject per country of origin.

Regarding to the number of patent applications per country was verified that more than $90 \%$ of them came from China. In second and third positions, Korea and the United States stand out, which together represent only $4.5 \%$ of total retrieved patent applications. The research showed that China has a much higher number of patent applications related to wind-powered desalination technologies than other countries, although $30 \%$ of these Chinese applications refer to utility model patents.

The research also revealed a clear differentiation in inventive activity type between the countries. It is noted that China tends mainly to file requests aimed at improving the existing solutions. On the other hand, deposits made by the Korea and the United States propose more disruptive innovations for the technology, different from the current state of the art.

This significant number of Chinese applications is justified by the substantial increase in water demand in the country, especially in coastal regions. The supply and demand imbalance in Chinese coastal areas is even worse than in its inland areas because of the need to support more population and industries with less water resources. Economic development and industry are much more advanced in coastal areas compared with inland China, this results in more stress on water resources in these areas. The broad literature shows that the China 


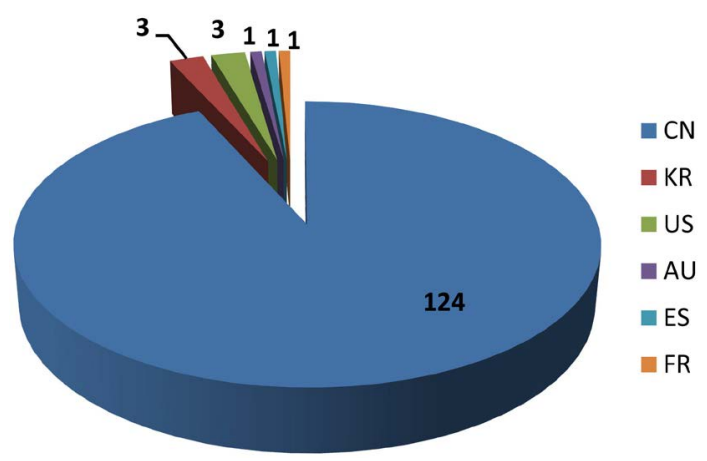

Figure 2. Number of applications of wind-powered desalination per country of origin retrieved from the Derwent Innovations Index database, indexed between 2000 and 2017 (own research).

started research on seawater desalination about 60 years ago. In 1984, China's State Oceanic Administration founded, in Tianjin, the Institute of Seawater Desalination and Multipurpose Utilization to facilitate research on seawater desalination technologies and development strategies. China has been developing ambitious goals for its seawater desalination industry since 2005. The goal for the total capacity of desalination was set $2.5-3$ million $\mathrm{m}^{3} / \mathrm{d}$ for 2020 [28] [29].

Regarding to wind power, China continues to maintain a strong momentum in the rapid development of wind power equipment production and wind farm development. China's wind power sector is one of the often-cited success stories of low-carbon energy development in emerging economies. The country has consolidated its role as the global leader of wind power, adding $33 \mathrm{GW}$ of new installed capacity. This represents a market share of 51.8\% [30].

In this context, the integration of the desalination process with wind energy has been increasing significantly in China, since that this technological solution has been considered one of the most promising to solve the water scarcity in the country.

\subsection{Profile of the Applicants}

Figure 3 shows the profile of the patent applicants in the field of wind-powered desalination. This analysis also aims at identifying the main patent applicants, whether companies, universities or research centers, in other words, the institutions that are investing in research and development (R \& D) of this technological field.

According to Figure 3, it is possible to conclude that the technological development of wind-powered desalination in the world is being promoted similarly by companies, universities/research centers, and independent researchers (individuals). Of the total deposits recovered, about $35 \%$ belong to individuals who do not have links with companies or other research centers/universities, $32 \%$ to companies, and the remaining $32 \%$ to universities and research centers. The research identified that first patent applications on the subject were received in 2000 , which leads to the conclusion that this topic is relatively recent in the 


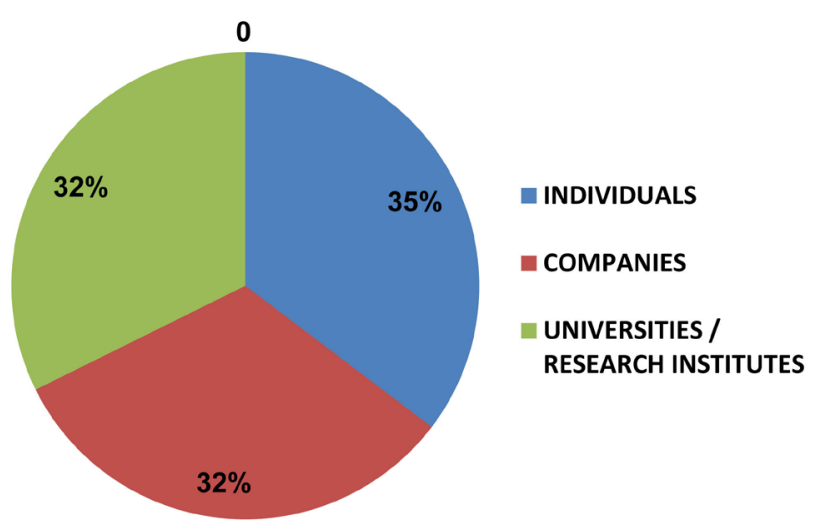

Figure 3. Main patent applicants in the field of wind-powered desalination of the seawater, retrieved from the Derwent Innovations Index database, indexed between 2000 and 2017.

scientific community. As a result, it is expected that companies, universities and research centers have an approximate number of deposits, reflecting the common interest of these actors in progress of the wind-powered desalination during the analysed period.

Universities accounted for $23 \%$ of the applications, and they are all Chinese. Hohai University stood out with 7 patent applications, while the Anhui University of Technology presented five applications. The research also showed that the companies presented similar number of patent applications, which leads to the conclusion that these companies are likely in the same stage of technological development.

\subsection{Technological Trends of the Sector}

The interaction between basic science and technological development can be studied with the help of technological indicators such as the patents. The use of information extracted from patent documents, granted or just requested, are essential in the interpretation of the main technological trends of a specific industry.

In this article, the identification of the technological trends of the wind-powered desalination sector was made through the reading of the patent applications abstracts. The main technological trends found in this research are shown in Figure 4. The identification of these trends can be strategic for the strengthening of the wind-powered desalination industry in the world.

Figure 4 shows that the integration of the wind energy with the osmosis reverse technology in desalination plants was the technological field that accounted for the highest number of patent applications (44), in other words, about $33 \%$ of total retrieved. RO is one of the most used technologies in the desalination industry. The technology uses pressure to separate two solutions with different concentrations with a semipermeable membrane. The main components of the RO system are the membrane modules, high pressure pumps, and devices to produce and recover energy as necessary. Among available water 

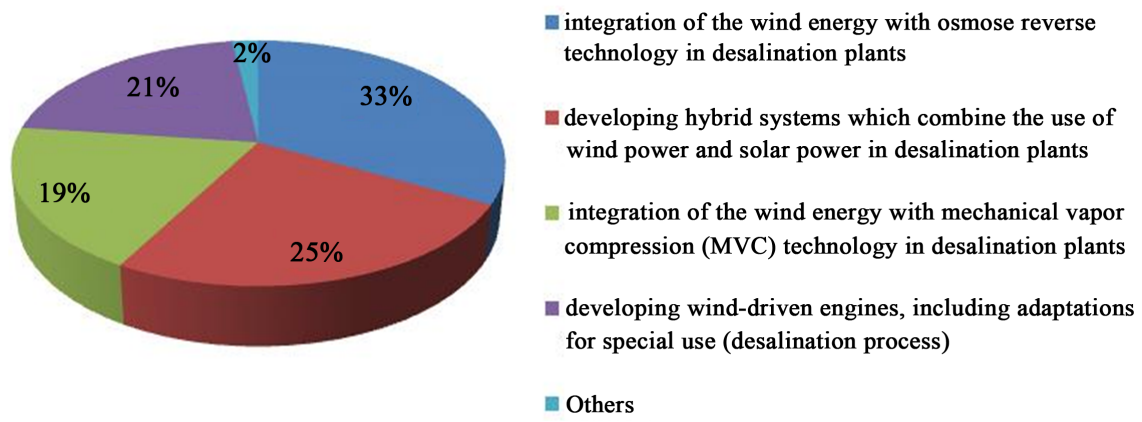

Figure 4. Breakdown of patent applications by technological trend mentioned in the abstracts.

desalination systems, reverse osmosis plants have been extensively employed in recent years, primarily by virtue of their low energy requirements compared to other reasonable methods [31]. It is one of the most appropriate desalination processes for combining with various renewable energy sources, such as solar and wind. The only electrical energy required by the process is for pumping the water to a relatively high operating pressure. In this sense, the use of wind turbines may reclaim part of the energy. Operating pressures vary between 10 and 25 bar for brackish water and 50 - 80 bar for seawater [32]. In short, the expressive number of patents about wind power integrated with RO technology can be justified by the low energy consumption of this technology and the possibility of modularization of the process, which facilitates both operation and maintenance of the system.

The analysis of this patent applications group showed innovations in RO processes and equipment directed for coastal and island communities, since that these regions have high wind energy potential. In this research, the patent applications with this subject have had the C02F-001/44 classification from IPC, which refers to water treatment involving membrane technologies.

According to Figure 4, the second technological field most frequent in the analysis, in 33 applications (about 25\% of total retrieved), reflects the trend of developing hybrid systems which combine the use of wind power and solar power in desalination plants. In a hybrid system, different power sources can be combined to maintain the energy supply to a desalination unit when one of them is unavailable. The major challenge for combining desalination process with wind energy is the intermittence and fluctuation of wind, which can bring many risks and difficulties to the operation and control of desalination system. Moreover, the power variations have an adverse effect on the performance and component life of certain desalination equipment. Back-up systems might be integrated into the system to reduce this effect. However, there is the alternative to integrate wind energy with other energy source, either conventional or renewable energy, such as solar PV or thermal. This research has identified that the hybridization of wind and solar power is one of the most promising and effective alternatives to overcome the intermittence and fluctuation of wind power in de- 
salination units. The patent applications with this subject have had the C02F-001/14 classification from IPC, which refers to use of solar energy in water treatment.

Although with a lower frequency in relation to the two technological fields mentioned previously, the analysis also identified 26 applications (19\% of total retrieved) about the integration of the wind energy with Mechanical Vapor Compression (MVC), as shown in Figure 4. The MVC technology is classified as a thermal desalination process since it involves the evaporation of seawater. The MVC desalination system is generally used for small scale and medium scale desalination units. The energy for evaporating the seawater comes from the vapor compression reheating by mechanical compressor rather than direct heating. Although it is a thermal process, electrical energy is necessary to activate the compressor of the unit. In a wind energy powered desalination system, the compressor is driven either directly by the mechanical energy of the wind turbines or indirectly by the electrical power from wind power generator. Although the MVC process consumes more energy than other desalination methods such as $\mathrm{RO}$, the additional advantages of relatively simple plant design and more robustness of fewer operation problems to power fluctuations attract several researches' attentions [33] [34] [35].

The research indicated the great potential of the MVC technology in the integration with the desalination process because of the advantages mentioned above. Membrane desalination technologies require complex pretreatment systems and high maintenance costs, such as membrane replacement over the lifetime of the plant, which is a big challenge of Reverse Osmosis in remote coastal areas and islands. In this sense, thermal-based desalination demands much simpler pretreatment processes compared with membrane-based methods, which makes the MVC technology a good choice to remote locations.

Figure 4 also shows that 28 applications (21\% of total retrieved) had as technological focus innovations in wind-driven engines. This result reflects the trend in the development of wind turbines and extra equipment designed to avoid wind fluctuation and intermittency, like energy storages systems and pressure or flow stabilized systems. Moreover, the research also showed the interest of the sector in technological solutions that enable wind turbines to operate at low speeds, that are essential for a reliable energy production since that many regions have available wind speeds that are low (such as 3 or $4 \mathrm{~m} / \mathrm{s}$ ).

\section{Conclusions}

The seawater desalination using renewable energy has become a key technology to solve the water scarcity problem in the world in an environment-friendly manner. Like other sources of renewable energy, wind energy is developing toward conventional, competitive and reliable energy technology. Technological improvements have continuously reduced the costs of this type of energy, especially on land, which makes the use of wind energy, a strategic option for problems related to water and energy.

Publications about patents are important sources of technological information 
which allows the evaluation of the development of new technologies and their impact on society. They provide a foundation for the strategic planning and the decision-making process of public and private institutions. Moreover, it is one of the main tools to map the directions technologies are taking. Based on the analysis of the patent data obtained by this research, we conclude that desalination technologies involving wind power can be characterized as a recent technological field which is constantly growing, especially since 2003 .

China plays the leading role in the technological development of the field as it clearly stands out among the other countries. This significant number of Chinese applications demonstrates the country's interest in finding solutions to the water shortages affecting several Chinese cities. The imbalance between supply and demand for water in the country is worrying, especially in coastal regions, where economic and industrial development is much more intense than in the continental regions.

The analysis of the technology trends demonstrates the potential of the innovations that are being developed to combine the wind power and the desalination process, especially using the Reverse Osmosis technology. Similar to other renewable energies, overcoming intermittence of the wind is an important technological problem for future researches and the solution that is developing for this problem involves mainly integrating of the wind energy with other kinds of energy, like solar energy. The trend in the development of wind engines technologies to be used in desalination plants can increase the expectation of future new wind-powered desalination installation in the world. Wind-powered desalination is one of the most promising options for seawater desalination, especially in coastal areas and islands where the wind power is usually much higher than the solar power, which shows how important scientific development is to the progress of this technology.

\section{Acknowledgements}

This study was financed in part by the Coordenação de Aperfeiçoamento de Pessoal de Nível Superior-Brasil (CAPES)-Finance Code 001. We would also like to thank the International Virtual Institute for Global Change (IVIG) for the possibility to interact with experts in renewable energy sources.

\section{Conflicts of Interest}

The authors declare no conflicts of interest regarding the publication of this paper.

\section{References}

[1] Shiklomanov, I. (1993) World Fresh Water Resources. Water Crisis a Guide to World's Fresh Water Resources. Oxford University Press, Oxford.

[2] United Nations World Water Assessment Programme (2015) Water for a Sustainable World. The United Nations World Water Development Report 2015. UNESCO, 
Paris.

[3] Mohammed, M.B. (2011) Low Cost Nanomaterials for Water Desalination and Purification. Final Technical Report, United Nations-UNESCO. http://www.unesco.org/new/fileadmin/MULTIMEDIA/FIELD/Cairo/Desalination \%20Final\%20UNESCO\%20report.pdf

[4] Qiblawey, H.M. and Banat, F. (2008) Solar Thermal Desalination Technologies. Desalination, 220, 633-644. https://doi.org/10.1016/j.desal.2007.01.059

[5] International Desalination Association (2015) Desalination by the Numbers.

[6] Al Hashemi, R., Zarreen, S., Al Raisi, A., Al Marzooqi, F. and Hasan, S. (2014) A Review of Desalination Trends in the Gulf Cooperation Council Countries. International Interdisciplinary Journal of Scientific Research, 1, 72-96.

[7] Ma, Q. and Lu, H. (2011) Wind Energy Technologies Integrated with Desalination Systems: Review and State-of-the-Art. Desalination, 277, 274-280.

https://doi.org/10.1016/j.desal.2011.04.041

[8] Buros, O.K. (2000) The ABCs of Desalting. 2nd Edition, Inter-National Desalination Association, Topsfield, MA.

[9] Rosa, D.J.M. (2013) Photovoltaic Systems for the Desalination of Water for Human Consumption: A Study of Its Viability and Configurations. Doctoral Thesis, Universidade de São Paulo.

[10] Habert, A.C., Borges, C.P. and Nobrega, R. (2006) Membrane Separation Processes. Série Escola Piloto de EngenhariaQuímica COPPE/UFRJ. Rio de Janeiro: E-papers ServiçosEditoriais Ltda.

[11] Manju, S. and Sagar, N. (2017) Renewable Energy Integrated Desalination: A Sustainable Solution to Overcome Future Fresh-Water Scarcity in India. Renewable and Sustainable Energy Reviews, 73, 594-609.

https://doi.org/10.1016/j.rser.2017.01.164

[12] International Renewable Energy Agency and IEA-ETSAP (2012) Water Desalination Using Renewable Energy: Technology Brief. The Energy Technology Systems Analysis Programme.

https://www.irena.org/DocumentDownloads/Publications/IRENA-ETSAP\%20Tech \%20Brief\%20I12\%20Water-Desalination.pdf

[13] Shaikh, F., Ji, Q. and Fan, Y. (2015) The Diagnosis of an Electricity Crisis and Alternative Energy Development in Pakistan. Renewable and Sustainable Energy Reviews, 52, 1172-1185. https://doi.org/10.1016/j.rser.2015.08.009

[14] Cipollina, A. and Micale, G. (2010) Coupling Sustainable Energy with Membrane Distillation Processes for Seawater Desalination. Proceedings of 20101 st International Nuclear and Renewable Energy Conference, Amman, Jordan, 21-24 March 2010, 1-6. https://doi.org/10.1109/INREC.2010.5462593

[15] European Union (2008) ADIRA Handbook, a Guide to Desalination System Concepts, Euro-Mediterranean Regional Programme for Water Management (MEDA).

[16] Global Wind Energy Council (2014) Global Wind Statistics 2014. Brussels.

[17] Sawin, J.L., Sverrisson, F. and Rickerson, W. (2015) Renewables 2015-Global Status Report. Annual Reporting on Renewables: Ten Years of Excellence (REN21). http://www.ren21.net/wp-content/uploads/2015/07/REN12-GSR2015_Onlinebook_ low1.pdf

[18] International Energy Agency (2015) Energy Technology Perspectives 2015 Mobilizing Innovation to Accelerate Climate Action. http://www.iea.org/etp/etp2015/

[19] García-Rodríguez, L. (2003) Renewable Energy Applications in Desalination: State 
of the Art. Solar Energy, 75, 381-393. https://doi.org/10.1016/j.solener.2003.08.005

[20] Raluy, R.G., Serra, L. and Uche, J. (2005) Life Cycle Assessment of Desalination Technologies Integrated with Renewable Energies. Desalination, 183, 81-93. https://doi.org/10.1016/j.desal.2005.04.023

[21] Mahmoudi, H., Spahis, N., Goosen, M.F., Sablani, S., Abdul-Wahab, S.A., Ghaffour, N. and Drouiche, N. (2009) Assessment of Wind Energy to Power Solar Brackish Water Greenhouse Desalination Units: A Case Study from Algeria. Renewable and Sustainable Energy Reviews, 13, 2149-2155. https://doi.org/10.1016/j.rser.2009.03.001

[22] Molina, V.G., Marca, M.A. and Hoehn, K. (2009) Designing Membrane Systems for the Coming Future: Perth II Desalination Plant. IDA World Congress, Atlantis, Dubai, UAE.

[23] Jones, L.E. and Olsson, G. (2017) Solar Photovoltaic and Wind Energy Providing Water. Global Challenges, 1, Article ID: 1600022. https://doi.org/10.1002/gch2.201600022

[24] Porter, A.L., Roper, A.T., Mason, T.W., Rossini, F.A. and Banks, J. (1991) Forecasting and Management of Technology. Wiley Series in Engineering and Technology Management, Estados Unidos.

[25] Alencar, M.S.M. (2008) Future Study through the Application of Techniques of Technological Prospection: The Case of Nanotechnology. Doctoral Thesis. Universidade Federal do Rio de Janeiro.

[26] Mueller, G. (2007) Roadmapping. Embedded Systems Institute. http://www.gaudisite.nl

[27] World Intellectual Property Organization (2018) Utility Models. http://www.wipo.int/patents/en/topics/utility_models.html

[28] Zheng, X., Chen, D., Wang, Q. and Zhang, Z. (2014) Seawater Desalination in China: Retrospect and Prospect. Chemical Engineering Journal, 242, 404-413. https://doi.org/10.1016/j.cej.2013.12.104

[29] Gao, C.J. (2003) Brief Discussion of Seawater Desalination. Chem. Technol. Economy., 11, 24-26.

[30] World Wind Energy Association (2016) Quarterly Bulletin.

[31] Koklas, P.A. and Papathanassiou, S.A. (2006) Component Sizing for an Autonomous Wind-Driven Desalination Plant. Renewable Energy, 31, 2122-2139. https://doi.org/10.1016/j.renene.2005.09.027

[32] Eltawil, M.A., Zhao, Z. and Yuan, L. (2009) A Review of Renewable Energy Technologies Integrated with Desalination Systems. Renewable and Sustainable Energy Reviews, 13, 2245-2262. https://doi.org/10.1016/j.rser.2009.06.011

[33] Plantikow, U. (1999) Wind-Powered MVC Seawater Desalination-Operational Results. Desalination, 122, 291-299. https://doi.org/10.1016/S0011-9164(99)00049-1

[34] Karameldin, A., Lotfy, A. and Mekhemar, S. (2003) The Red Sea Area Wind-Driven Mechanical Vapor Compression Desalination System. Desalination, 153, 47-53. https://doi.org/10.1016/S0011-9164(02)01092-5

[35] Ismail, T.M., Azab, A.K., Elkady, M.A. and Abo Elnasr, M.M. (2016) Theoretical Investigation of the Performance of Integrated Seawater Desalination Plant Utilizing Renewable Energy. Energy Conversion and Management, 126, 811-825. https://doi.org/10.1016/j.enconman.2016.08.002 